\title{
Learning and Memory Enhancing Activity of Polyherbal Formulation on Streptozotocin Induced Memory Impairment in Rats via Reducing Mitochondria-Targeted Cytochrome
}

\author{
Deepa Shukla ${ }^{1,2}$, Sajal Srivastava ${ }^{2, *}$, Talha Jawaid ${ }^{3}$
}

Deepa Shukla ${ }^{1,2}$, Sajal

Srivastava ${ }^{2, *}$, Talha Jawaid ${ }^{3}$

'School of Pharmacy, Sharda University, Greater Noida, Uttar Pradesh, INDIA.

${ }^{2}$ Amity Institute of Pharmacy, Amity University Uttar Pradesh, Lucknow Campus, Lucknow 226010, Uttar Pradesh, INDIA.

${ }^{3}$ Department of Pharmacology, College of Medicine, Al Imam Mohammad Ibn Saud Islamic University, P.O. Box 11623, Riyadh 11544, SAUDI ARABIA.

\section{Correspondence}

\section{Sajal Srivastava}

Amity Institute of Pharmacy, Amity

University Uttar Pradesh, Lucknow

Campus, Lucknow 226010, Uttar Pradesh, INDIA.

Phone no: 8808796867;

E-mail: ssrivastava2@|ko.amity.edu

History

- Submission Date: 17-10-2020;

- Review completed: 01-12-2020;

- Accepted Date: 08-12-2020.

DOI : 10.5530/pj.2021.13.33

Article Available online

http://www.phcogj.com/v13/i1

Copyright

(c) 2021 Phcogj.Com. This is an openaccess article distributed under the terms of the Creative Commons Attribution 4.0 International license.

\begin{abstract}
Introduction: Neurodegenerative diseases and/or brain injury may occur due to mild to severe memory disorders in which Alzheimer's disease (AD) is defined as degradation of neurons and there is no effective therapy or cure for the disease. The intention behind this study was to determine memory enhancing effect of an Ayurvedic polyherbal formulation (PHF) in Streptozotocin-induced memory deficit experimental animal models. Methods: Polyherbal formulation (PHF) was a suspension of three plant extracts i.e. Alpinia galanga, Glycerrhiza glabra and Convolvulus pluricaulis along with other excipients. Different behavioral animal models like Social recognition test (SRT), Morris water maze (MWM) test, Pole climbing test (PCT) and Elevated plus maze (EPM) test were used to evaluate efficacy of Polyherbal formulation (PHF) in learning and memory process of animals. Gene expression was performed by RT-PCR and western blot. Results: Results indicated that time of social recognition during trial 2 (SIT2) was reduced significantly $(\mathrm{P}<0.01)$ due to $\mathrm{PHF}$ administration. In MWM test, treatment with $\mathrm{PHF}$ significantly $(P<0.01)$ reduced $[F(4,20)=6.9]$ latency to reach hidden platform from session 3. Similarly, PHF was also found effective in pole climbing test and EPM test. RT-PCR results showed p53 regulates the $\mathrm{Bcl}-2$ family proteins its expression in the given experiment was appreciably reduced in PHF (200mg/ $\mathrm{kg})$. NR1, NR2B and GAP-43 proteins leads to reduction of brain cell damage. Conclusion: Thus, PHF may be an effective formulation for learning and memory process against STZ-induced memory impairment.
\end{abstract}

Key words: Alpinia galanga, Glycerrhiza glabra, Convolvulus pluricaulis, Pole climbing test, Elevated plus maze, Social recognition test.

\section{INTRODUCTION}

Alzheimer's disease $(\mathrm{AD})$ is defined as degradation of neurons and there is no effective therapy or cure for the disease. ${ }^{1}$ It has affected nearly 40 million people around the globe and that is expected to increase in the coming years. ${ }^{2}$ People with disturbed cognition is in a transition stage between declining due to aging and other clinical syndromes associated with Alzheimer's disease. ${ }^{3}$ Neurodegenerative diseases and/or brain injury may occur due to mild to severe memory disorders, all are linked to acquisition, consolidation and retrieval. $^{4}$

A possible step towards standard therapy for the treatment is to slowdown the progression of disease. Thus, research on disease origination and pathophysiology is required along with the testing of new drugs. The medications for treatment of cognitive impairment may cause various side effects and other consequences. To avoid these undesired effects to drugs, the extensive research has been going on medicinal plants and natural supplements due to their wide history of neuroprotective and brain boosting drugs with no side effects. Medicinal plants have been used in various cognitive improving abilities like memory, motivation, attention, intelligence, and concentration. ${ }^{5}$ They are also referred as nootropic drugs that enhance cognition and maintain healthy emotional state, process of learning and motor control. ${ }^{6}$

Ayurveda as an ancient system of medicine of India has gaining importance worldwide due to its disease preventive and health promoting approach. ${ }^{7}$ In the present study, an Ayurvedic Polyherbal formulation was prepared by incorporating three traditional herbs i.e. Alpinia galanga (AG), Glycyrrhiza glabra (GG) and Convolvulus pluricaulis (CP). The abovementioned herbs were selected due to their uses as folk medicine in cognition enhancing and memory boosting effects. Alpinia galanga, it is a well-known medicinal plant containing mild spicy fragrance belongs to family Zingiberaceae. ${ }^{8}$ It has been used in the Asian countries for the treatment of oxidative stress, stomachache, diarrhea, ulcer, inflammation, diabetes mellitus, spasm and microbial and insecticidal infection. ${ }^{9}$ It is a class of edible group and popular nervine tonic herb in India. Glycyrrhiza glabra L. is a Leguminosae plant, possess several bioactive compounds like glycyrrhizin, glycyrrhetinic acid, octanoic acid etc. that are responsible for neuroprotective, hepatoprotective, immunomodulatory and anticancer activities. ${ }^{10,11}$ Convolvulus pluricaulis Linn. is a native plant of India used as a neuroprotective and memory enhancer herb since ancient times. ${ }^{12}$ It belongs to family

Cite this article: Shukla D, Srivastava S, Jawaid T. Learning and Memory Enhancing Activity of Polyherbal Formulation on Streptozotocin Induced Memory Impairment in Rats via Reducing Mitochondria-Targeted Cytochrome. Pharmacog J. 2021;13(1): 230-40. 
Convolvulaceae and used in the treatment of diabetes, ulcer, anxiety, liver diseases and oxidative stress. ${ }^{13,14}$

Therefore, in this study, the memory boosting efficacy of Polyherbal formulation (PHF) was evaluated in different behavioral models with a thought to neurodevelopmental origins in memory deficit disorder such as Schizophrenia, Dementia, Alzheimer's and Autism. In addition, to evaluate the biochemical level of Polyherbal formulation (PHF) in brain by estimating enzymatic levels and level of metabolic enzyme acetylcholinesterase (AChE)

\section{MATERIAL AND METHODS}

\section{Chemicals and reagents}

Donepezil, Streptozotocin, Propyl paraben, Methyl paraben, Tween 80 and Sodium carboxy methyl cellulose were purchased from Sigma Aldrich, USA. All other solvents were of analytical grade and distilled water was used throughout the study. Albino Wistar rats were used for evaluating the effect of poly herbal formulation (PHF) in different experiment models.

\section{Preparation of formulation made up of herbs}

The formulation of herbs was prepared by mixing $0.5014 \mathrm{~g}, 0.3343 \mathrm{~g}$ and $0.3343 \mathrm{~g}$ of Alpinia galanga (AG), Glycerrhiza glabra (GG) and Convolvulus pluricaulis (CP) extracts, respectively followed by addition of parabens (Propyl paraben, $0.02 \%$, w/v and Methyl paraben, $0.2 \%$, $\mathrm{w} / \mathrm{v})$, tween $80(0.1 \%, \mathrm{w} / \mathrm{v})$ and a little amount of sodium carboxy methyl cellulose $(0.5 \%, \mathrm{w} / \mathrm{v})$ then uniformly triturated to form a smooth paste. The paste was rinsed with distilled water $(100 \mathrm{ml})$ and vortexed using mechanical stirrer $(500 \mathrm{rpm})$ to get suspension. The formulation was found stable upto 90 days of storage.

\section{Experimental design and drug administrations}

The effect of Alpinia galanga (AG), Glycerrhiza glabra (GG) and Convolulus pluricaulis (CP) extracts and their formulation was evaluated in experimental models of memory impairment due to streptozotocin (STZ) administration. The test drug along with standard and vehicle were giving for 14 days. Intracerebroventricular (ICV) streptozotocin (STZ) was given prior to test drug administration.

\section{Streptozotocin (STZ) induced memory impairment and grouping of animals}

The test compounds and standard drug were administered for 14 days and behavioral assessments were carried out from $14^{\text {th }}$ day onwards. Animals were anesthetized using ether and STZ (3 mg/kg) was given to animals on $1^{\text {st }}$ and 3 rd day through intracerebroventricular (ICV) route. Injections for intracerebroventricular (ICV) route were made with hypodermic needle that was attached to Hamilton microliter syringe. The needle was perpendicularly inserted to the skull of animals to reach into the brain. Streptozotocin (STZ) was prepared freshly by dissolving into cerebrospinal fluid (CSF) $(25 \mathrm{mg} / \mathrm{ml})$ solution. The concentration was adjusted in such a way to deliver only required amount of drug (10 $\mu l)$ through injection.

Animals were divided into seven groups each containing six animals. Group - 1 Control, Vehicle treated, intra-peritoneal (p.o.); Group - 2 Toxic group, STZ (icv); Group - 3 Donepezil ( $5 \mathrm{mg} / \mathrm{kg}$, i/p); Group - 4, 5 and 6 received extract of $A G, G G$ and $C P$, respectively in the dose of $200 \mathrm{mg} / \mathrm{kg}$, p.o.; and Group - 7 and 8 received PHF (200 and $400 \mathrm{mg} /$ $\mathrm{kg}$, p.o., respectively).

\section{Assessment of learning and memory}

\section{Social recognition test (SRT)}

Social Recognition Test (SRT) was performed on male Wistar rats weighing 220-240 g. Animals memory were impaired by administration of STZ. STZ was administered on $14^{\text {th }}$ day to the test animals. The effect of test drugs were determined by introducing unfamiliar juvenile in the cages of animals as social stimuli. The time recorded as T1 that test animal spent with the juvenile for 5 min interval and then juvenile rat was removed. T2 was recorded after $2 \mathrm{~h}$ when same juvenile was reintroduced into their cages. SRT of test animal was determined by significant reduction of in interaction time in trial 2 (T2) as compared to T1. The recognition index (RI) was calculated using following formula: $\mathrm{RI}=\frac{T:}{T 1}$

\section{Morris water maze (MWM) test}

Morris Water Maze (MWM) test was performed on male Wistar rats weighing 220-240 g. Animals memory were impaired by administration of STZ on $14^{\text {th }}$ day of treatment ${ }^{15}$. The arrangement was made with this test by placing the rats in a circular pool with dimensions of $45 \times 26$ $\times 20 \mathrm{~cm}$ which was filled with water. The pool was marked with four different starting points i.e. N-E-ES-WN. The animals were allowed to stay for $30 \mathrm{~s}$ if they were unable to escape themselves from the pool in $120 \mathrm{~s}$. The prior trials were given to each animal; daily four trials were given for five days before placing them into the pool. The effect of test drugs was determined by noting the escape latency time of the animals.

\section{Pole climbing test (PCT)}

Cook's pole climbing test apparatus was used to study the effect of test compounds on STZ induced memory impaired animals. The apparatus consists of a $25 \mathrm{~cm} \times 25 \mathrm{~cm} \times 40 \mathrm{~cm}$ chamber along with dim light and sound box. The electric shock was given to animals be grid floor of the chamber. The animals avoided electric stimulus by jumping onto the pole. This jumping was noted as an escape time of the animals to avoid foot shock. However, jumping on to the pole before shock due to buzzer sound was considered as avoidance. The experiment was terminated after 10 trials with intervals of $30 \mathrm{~s}$. The animals were given the respective treatment and again subjected to the test procedure for 5 consecutive days after the completion of training. A significant reduction in escape latency time was considered as successful retention of avoidance memory. ${ }^{16}$

\section{Elevated plus maze (EPM) test}

Elevated Plus Maze (EPM) test apparatus was used to study the effect of test compounds on STZ induced memory impairment animal model. The apparatus consists of two open and two closed arms with dimension of $16 \times 5 \mathrm{~cm}$ and $16 \times 5 \times 12 \mathrm{~cm}$, respectively. The apparatus height is such that it is $25 \mathrm{~cm}$ above from the floor. The animals were placed on the open arm of the EPM and noted the time taken by animals to move in different arms and the time consume by the animals was termed as transfer latency (TL). TL was assigned $90 \mathrm{~s}$ if one of the two arms was pushed gently. The animals were allowed to stay on the EPM for $10 \mathrm{~s}$ and then returned to the cages. After the completion of first day trial the memory retention of animals was examined. ${ }^{17}$

\section{Biochemical estimation}

\section{Malondialdehyde (MDA) estimation}

Malondialdehyde was estimated according to the method of Colado et al., 1997. Briefly, TCA and $\mathrm{HCl}(5 \mathrm{~N})$ were mixed with brain homogenate in which $2 \%$ TBA was added. The mixture was then heated at $900^{\circ} \mathrm{C}$ for $15 \mathrm{~min}$ followed by centrifugation for $10 \mathrm{~min}$ at $12000 \times$ g. The supernatant was isolated and measured at $532 \mathrm{~nm}$ using ELISA plate reader (Biotek, USA). The determined MDA in supernatant was expressed as nmoles/mg of protein. It was calculated using standard curve of Tetra ethoxy propane (TEP).

\section{Glutathione (GSH) estimation}

Gultathione level in animals were determined according to the method of Sharm and Gupta, 2001. Briefly, trichloroacetic acid was mixed with 
brain the homogenate in the ratio of 1:1 followed by centrifugation for $10 \mathrm{~min}$ at $12000 \times \mathrm{g}$. The supernatant was separated and mixed $(0.01$ $\mathrm{ml}$ ) a mixture containing 5,5-dithiobis (2-nitrobenzoic acid $(0.05 \mathrm{ml})$ and phosphate buffer $(0.2 \mathrm{ml}, \mathrm{pH} 8.5)$ with distilled water $(0.04 \mathrm{ml})$. The mixture was measure at $412 \mathrm{~nm}$ after vortexing using ELISA plate reader (Biotek, USA). The determined GSH in supernatant was expressed as $\mu \mathrm{g} / \mathrm{mg}$ of protein.

\section{Acetylcholine (AchE) activity assay}

Acetylcholine (AchE) activity in animals brain was determined according to the method of Das et al., 2001. The activity of AchE was measured at $412 \mathrm{~nm}$ using ELISA plate reader (Biotek, USA) and expressed in $\mu \mathrm{mol} / \mathrm{min} / \mathrm{mg}$ protein.

\section{RT-PCR (Reverse Transcriptional Polymerase Chain Reaction) analysis of $m R N A$ Expression}

TRIzol reagent was used to extract total RNA from the hippocampal tissue of the animals and cDNA Reverse Transcription Kit was used for reverse transcription. qPCR Master Mix (Thermo Scientific Luminaris) was used for performance of quantitative RT-PCR. The housekeeping gene for mRNA-specific primers were Bcl-2, Bak, Bax and $\beta$-actin. Mastercycler ep realplex was used for quantitative RT-PCR reactions for data analysis. The expression of gene after data analysis was calculated according to the method of Livak and Schmittgen. ${ }^{18}$

\section{Western Blot Analysis of protein expression}

Western Blot Analysis was performed on brain tissues obtained from the hippocampus region of the animals after $24 \mathrm{~h}$ of treatment. The tissues were homogenized with the buffer containing $\mathrm{NaCl}(50$ $\mathrm{nM} / \mathrm{L})$, EDTA (1 mM/L), SDS (0.5\%), Triton X-100 (1\%), Tris $\mathrm{HCl}$ $(20 \mathrm{mM} / \mathrm{L})$ and sodium deoxycholate (0.5\%). It was centrifuged for 20 min at $15,000 \times \mathrm{g}$. The samples $(50 \mu \mathrm{g})$ were ran on polyacrylamide gel and then transferred to PVDF membrane. It was blocked by milk solution (5\%) for $2 \mathrm{~h}$. Incubation of membrane was performed at $4{ }^{\circ} \mathrm{C}$ along with the specific antibodies i.e. mouse monoclonal anti- $\beta$-actin (1:10000; dilution), NR2B (1:1000, dilution), NR1 (1:1000, dilution), and GAP-43 (1:1000, dilution). The membrane was then incubated with conjugated anti-rabbit IgG (1:10000; dilution) horseradish peroxidaseconjugated goat anti-mouse IgG for a duration of 2 hours at a dilution of 1:2000 (at room temperature) anti mouse at room temperature for $1 \mathrm{~h}$ after washing with TBST. Detection was carried out by an enhanced chemiluminescence method and photographs were taken by Biospectrum Gel Imaging System. The data were normalized with the help of GAPDH (objective protein IOD Vs GAPDH protein IOD). ${ }^{19}$

\section{Statistical analysis}

Results are expressed as mean \pm S.E.M. Statistical analysis was carried out by One-way ANOVA and after that dunnett's multiple comparison assay was done. The results were significantly different at ${ }^{*} \mathrm{p}<0.05$, ${ }^{* *} \mathrm{p}<0.01$ and ${ }^{* * *} \mathrm{p}<0.001$ in comparison to control group.

\section{RESULTS}

\section{Effect of PHF using SRT on memory animals}

The effect of PHF was determined on $14^{\text {th }}$ day after memory impairment by STZ injection. Results showed that SRT for trial 2 was decreased as compared to trial 1 SRT in treated animals as compared to control group. The standard drug donepezil also prevent STZ induced memory impairment in animals as shown in Figure 1. Treatment with AG, CP and GG extracts at $200 \mathrm{mg} / \mathrm{kg}$ each have shown significant reduction in SIT2 $(\mathrm{P}<0.01)$ in comparison to SIT1 indicating prevention of STZ induced memory impairment. PHF was more effective than individual plant extracts in preventing STZ induced memory impairment. Further, difference in the recognition index of control, vehicle and STZ group, confirming impairment of memory (Figure 2). The recognition index was significantly lower in donepezil, plant extracts and PHF treated groups in comparison to memory impaired group.

\section{Memory enhancement effect of PHF using MWM test}

A significant decrease in latency time during the $4^{\text {th }}$ and $5^{\text {th }}$ sessions was observed in control and vehicle groups in comparison to the session 1 (Figure 3). ICV injection of STZ caused memory impairment in rats as shown by no significant reduction in latency time through session 5. Treatment with the standard drug donepezil prevented memory impairment as indicated by a significant reduction in latency time from third session onwards in comparison to the first session. At a dose of $200 \mathrm{mg} / \mathrm{kg}$, plant extracts caused amelioration of STZ induced memory impairment in rats. AG and GG significantly decreased the latency time during the 4th and 5th session while CP significantly reduced latency time during 5th session in comparison to session 1 . No significant change was observed between the latency times of session $1(\mathrm{P}>0.05)$ and session $2(\mathrm{P}>0.05)$ of all groups (Figure -3$)$. Results showed that PHF decreased latency for animals to reach the platform from session 3 onwards.

\section{Effect of PHF on STZ induced memory impairment in pole climbing test}

Results showed that there was a significant reduction in the latency time of treated animals on days 4 and 5, whereas in the STZ group, no significant reduction was seen throughout all days. The standard drug donepezil caused significant reduction in the latency time from day 3 onwards indicating prevention of STZ induced memory impairment. Treatment with AG, CP and GG extracts caused amelioration of STZ induced memory impairment as indicated by reduced latency time on day 4 and 5 . However, no change was seen between the latency time of day $1(\mathrm{P}>0.05)$ of all groups (Figure 4$)$. The PHF also significantly reduced latency time from day 3 onwards in STZ-injected rats.

\section{Effect of PHF on STZ induced memory impairment in EPM test}

Memory enhancement effect of PHF was determined using elevated plus maze (EPM) on days 14 and 15. Acquisition trial was given on 14th day and retention was studied $24 \mathrm{~h}$ after acquisition. As shown in Figure 5 , the transfer latency time in retention trial was significantly $(\mathrm{P}<0.01)$ lower that acquisition trial in control and vehicle groups. However, STZ group showed no significant change in retention latencies in comparison to acquisition trial, indicating impairment in learning and memory. Donepezil at $5 \mathrm{mg} / \mathrm{kg}$ significantly reduced latency time during retention trial in comparison to acquisition trial indicating prevention of memory impairment. Treatment with AG, CP and GG extracts caused amelioration of STZ induced memory impairment as indicated by significantly lower latency time in retention trial (Figure 5). The PHF also significantly reduced latency time during retention test in STZ-injected rats.

\section{Biochemical estimations}

\section{Effect of PHF on MDA level in STZ-induced amnesic rat brain}

The MDA level was increased in the cortex and hippocampus regions of the memory impaired rats significantly as compared to the control and vehicle groups. Treatment with donepezil reduced MDA levels in both brain regions significantly as compared to STZ group. Administration of $200 \mathrm{mg} / \mathrm{kg}$ of plant extracts significantly decreased MDA levels in cortex and hippocampus of STZ-injected rats. PHF treatment also caused significant decrease in MDA level in cortex and hippocampus of STZ injected rat brain (Figure 6). 


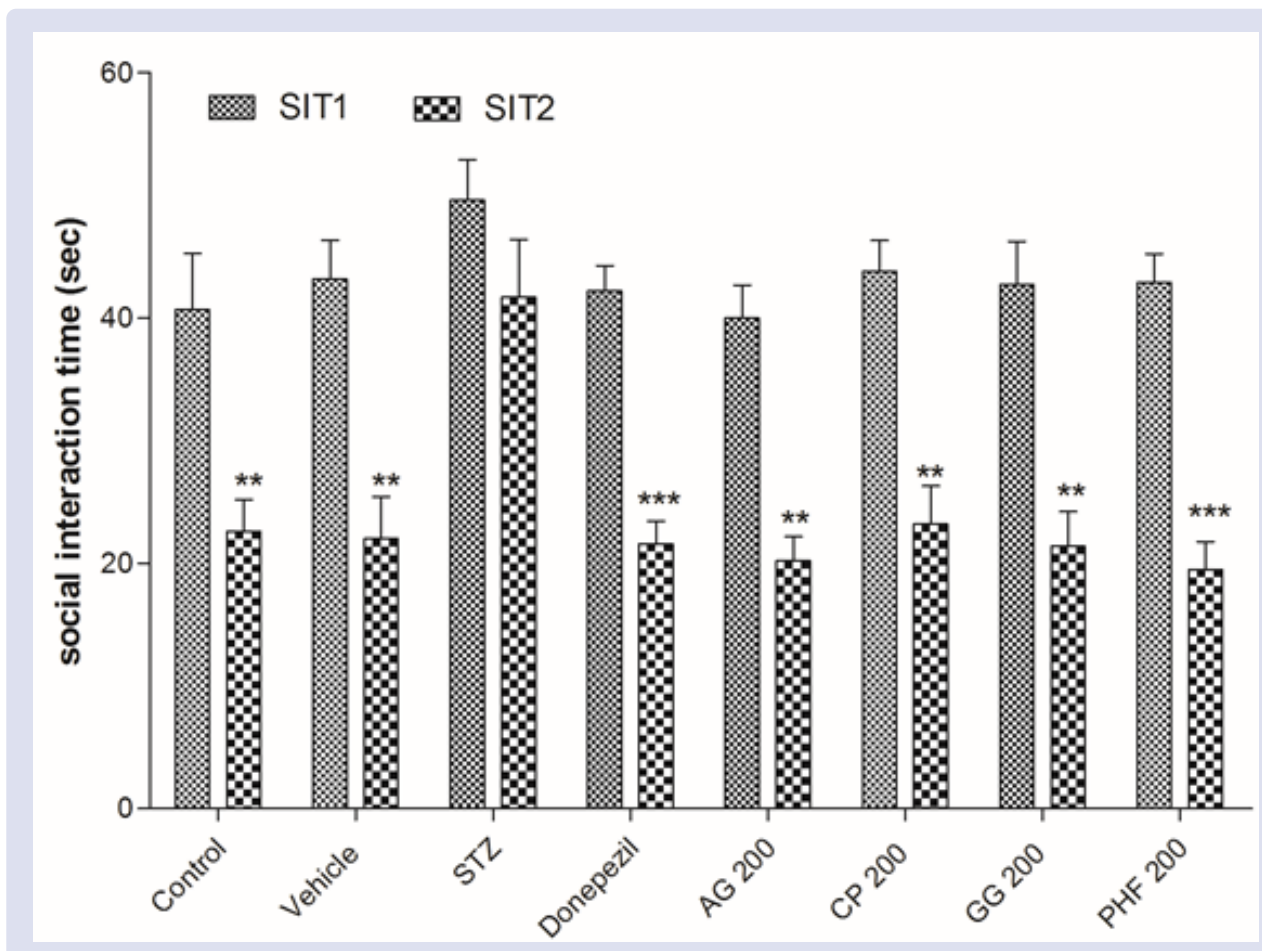

Figure 1: Effect of plant extracts and PHF on cognition impaired rats using the social recognition test. Results were presented as mean \pm S.E.M., significantly different at ${ }^{* *} \mathrm{P}<0.01$ and ${ }^{* * *} \mathrm{P}<0.001$ as compared to trial 1 of the respective group.

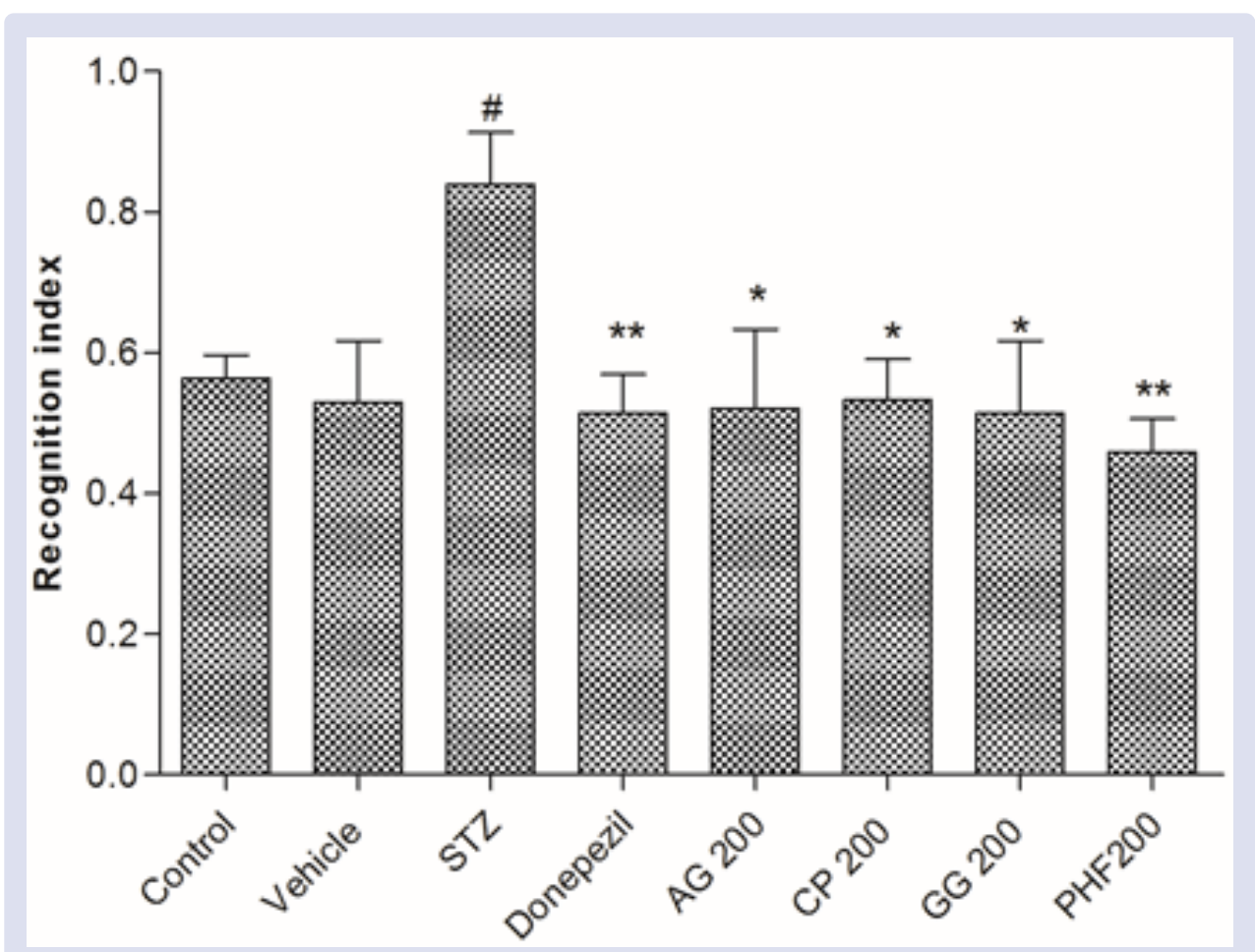

Figure 2: Effect of plant extracts and PHF on recognition index of STZ treated animals. Results were presented as mean \pm S.E.M., significantly different at \#P $<0.05$ as compared to control and vehicle groups and ${ }^{*} \mathrm{P}<0.05$ and ${ }^{*} \mathrm{P}<0.01$ as compared to the $\mathrm{STZ}$ group. 


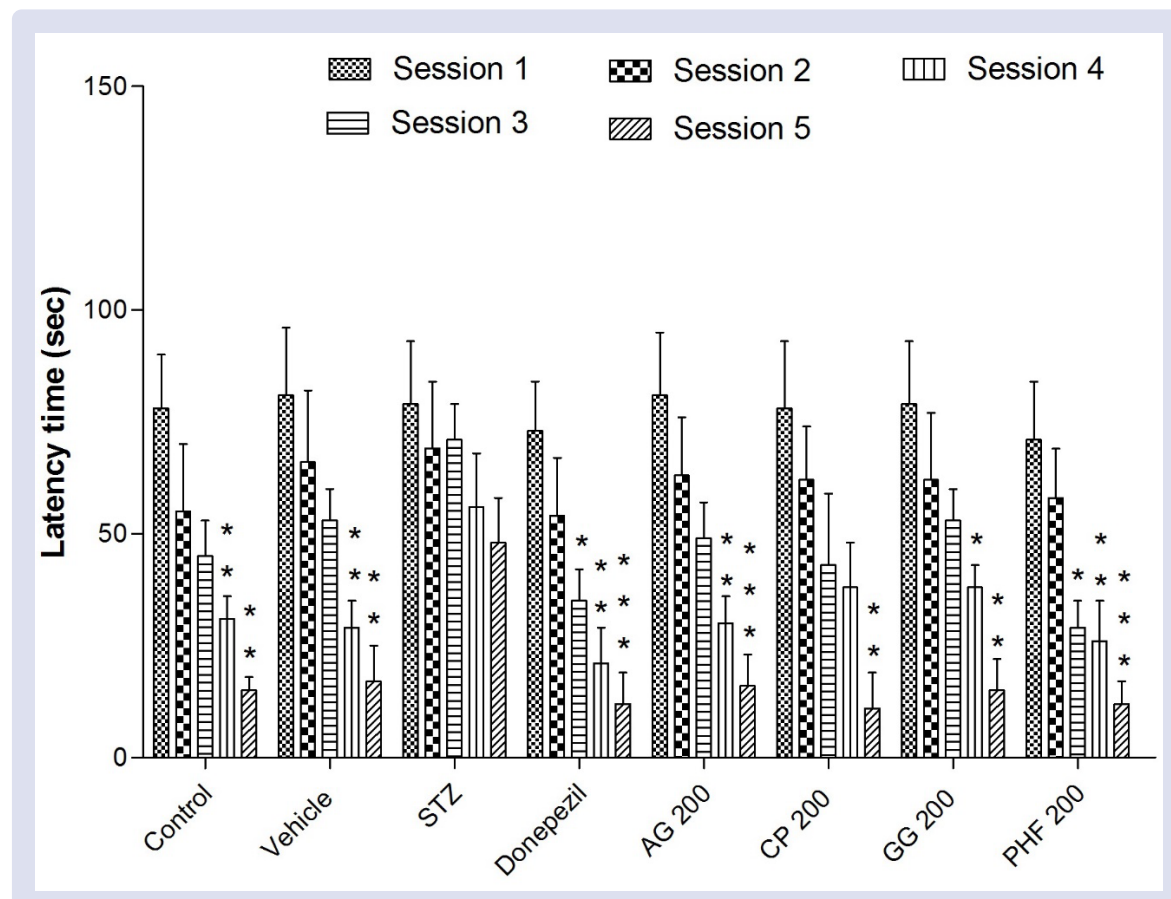

Figure 3: Effect of plant extracts and PHF in memory impaired rats using Morris water maze test. Results were presented as mean \pm S.E.M., significantly different at $\left({ }^{*} \mathrm{P}<0.05,{ }^{* *} \mathrm{P}<0.01\right.$ and ${ }^{* * * P}<0.001$ as compared to session 1 of the respective groups.

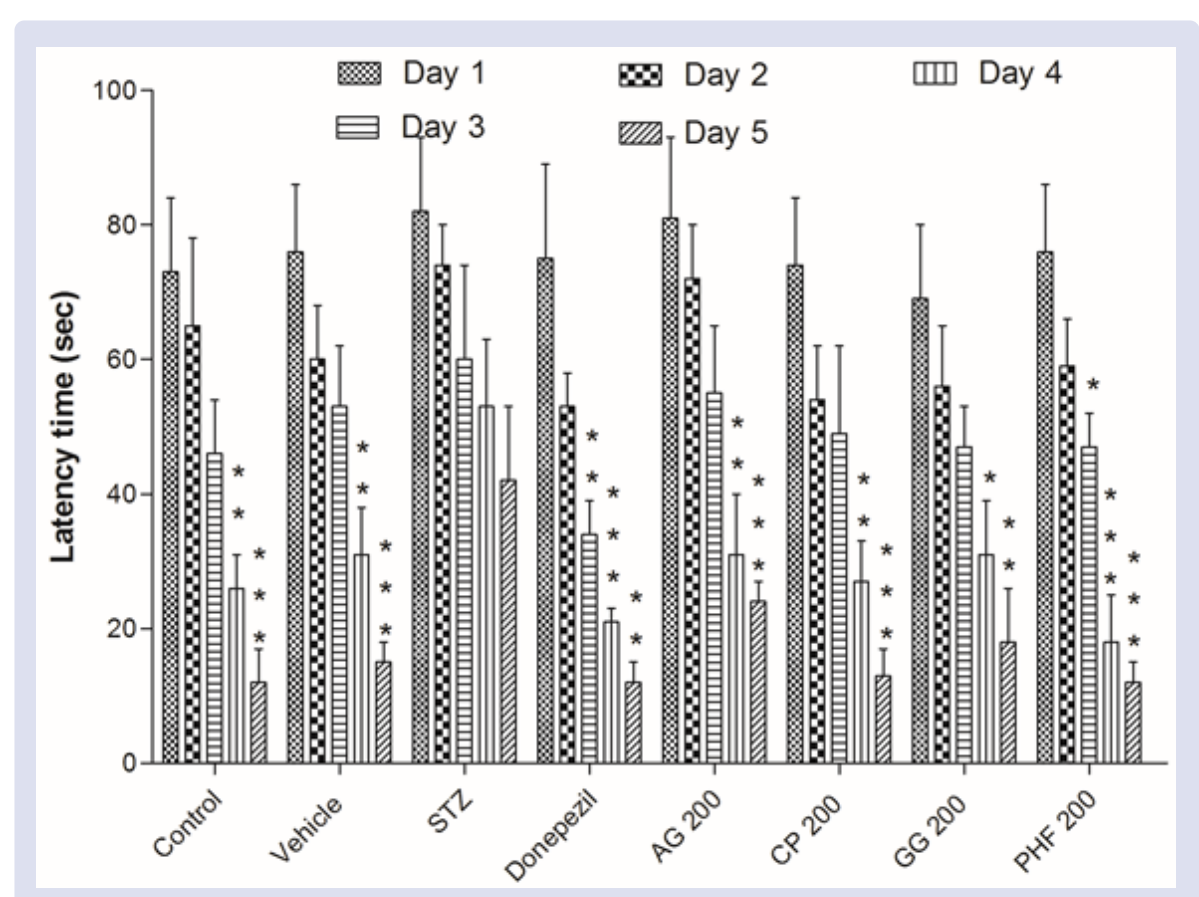

Figure 4: Effect of plant extracts and PHF in memory impaired rats using pole climbing test. Results were presented as mean \pm S.E.M., significantly different at ${ }^{*} \mathrm{P}<0.05$, ${ }^{* *} \mathrm{P}<0.01$ and ${ }^{* * *} \mathrm{P}<$ 0.001 as compared to day 1 of the respective groups. 


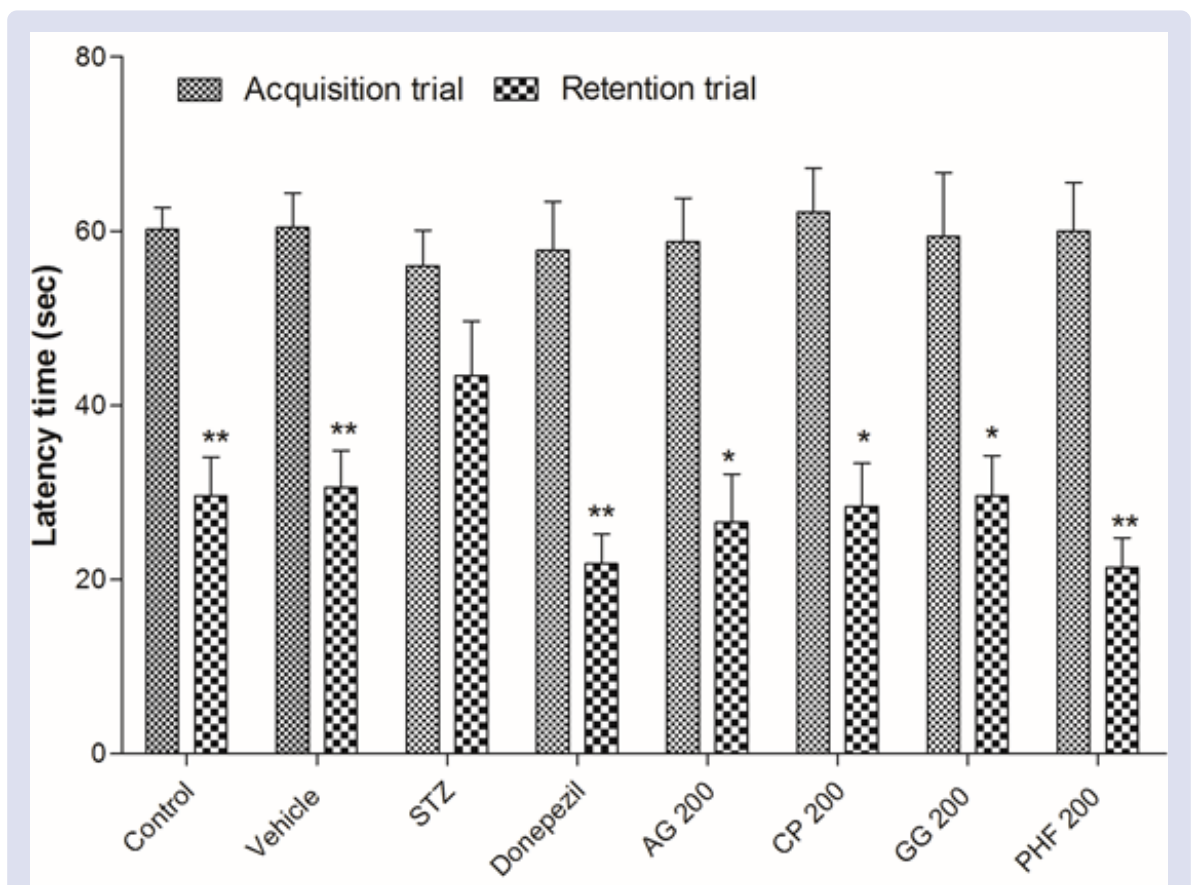

Figure 5: Effect of plant extracts and PHF in memory impaired rats using elevated plus maze test. Results were presented as mean \pm S.E.M., significantly different at $\left({ }^{*} \mathrm{P}<0.05,{ }^{* * P}<0.01\right.$ and ${ }^{* * * P}$ $<0.001$ as compared to retention trial of the respective groups.

\section{Effect of PHF on GSH level in memory impaired rats}

Effect of PHF was calculated by estimating the level of GSH in brain regions of rat using the calibration curve obtained with different concentration of glutathione. STZ administration caused reduction in GSH levels in brain regions as compared to control and vehicle groups. As shown in Figure 7, donepezil prevented reduction in GSH level in cortex and hippocampus regions significantly $(\mathrm{P}<0.01)$. Administration of plant extract prevented STZ induced reduction in GSH levels. AG, CC and GG extracts increased GSH levels significantly in STZ treated rat brain regions.

\section{Effect of PHF on AChE level in STZ-induced amnesic rat brain}

Results exhibited that administration of STZ caused increase in the AChE activity in both cortex and hippocampus regions of treated animals. Preventive treatment with donepezil significantly inhibited AChE activity in cortex $(\mathrm{P}<0.05)$ and hippocampus $(\mathrm{P}<0.01)$ of STZ injected rats (Figure 8). Administration of plant extract prevented elevation of AChE activity. AG, CC and GG extracts significantly decreased AChE activity in impaired memory rats. There was significant decrease in the AChE activity in brain regions of the rats treated with $200 \mathrm{mg} / \mathrm{kg}$ PHF (Figure 8).

\section{Effect of PHF on $m$ RNA expression and protein expression}

Expressions of Bcl-2, Bak, and Bax mRNA are demonstrated in for excluding the variations due amount and nature of RNA, the results recorded were adjusted according to the expression of GAPDH. Hippocampal tissue in STZ group was indicated by considerably amplified the levels Bak \& Bax and significantly declined the levels of Bcl2. Their levels were appreciably inverted in PHF $(200 \mathrm{mg} / \mathrm{kg})$. PHF 200 group showed best results which were almost comparable to STZ group. In comparison to STZ group, PHF $(200 \mathrm{mg} / \mathrm{kg})$ demonstrated more significant effect in up-regulation of Bcl-2 protein and down-regulation of $\mathrm{p} 53$ protein. In mitochondrial pathway cell apoptosis chiefly involves the Bcl-2 g. Bcl-2 and Bax (both are belong toBcl family) controls the secretion of proapoptotic factors from mitochondria. In the present study, Bax and Bak mRNA (proapoptotic) were down-regulated, while Bcl-2 mRNA and protein which are antiapoptotic were up-regulated in PHF $(200 \mathrm{mg} / \mathrm{kg}$ ) group opposite to STZ group. Also, p53 regulates the $\mathrm{Bcl}-2$ family proteins its expression in the given experiment was appreciably reduced in PHF $(200 \mathrm{mg} / \mathrm{kg})$ group opposite effect was recorded in STZ group. These findings indicated that PHF could exert its memory enhancement by interacting with these proteins (Figure 9).

Western blot analysis was carried out for recording the memory enhancer activity of PHF (200 mg/kg). NR1, NR2B, and GAP-43 levels in hippocampus of amnesic rats were significantly lower as compared to control group. Conversely, PHF groups showed significantly higher NR1, NR2B and GAP-43 protein levels as compared to STZ treated group. As shown in Figure 10 protein expressions of NR1 and NR2B were augmented by almost two times and five times in the hippocampus of mice of STZ group as compared to the mice of control group, whereas their expressions were appreciably reduced in PHF mice. NR1 expression was amplified by almost six-folds in sSTZ treated mice while PHF treated mice partially prevented this effect. Majorly two pathways are involved in cell apoptosis (death receptor pathway and mitochondrial pathways). Reported findings say that, interaction of death receptor and its ligand e.g., interaction of NR1/NR2B, are important for initiating apoptosis (extrinsic pathway). Prior studies have shown that by suppressing NR1,NR2B and GAP-43 proteins leads to reduction of brain cell damage. PHF $200 \mathrm{mg} / \mathrm{kg}$ showed a significant effect by shielding against STZ induced brain damage.

\section{DISCUSSION}

Pathogenesis of cognition impairment starts from temporal lobe or dysfunction of prefrontal part of brain. It can be ranging from mild cognitive impairment to dementia. ${ }^{20}$ Learning and memory processes are based on electro-chemical signaling, acts as a network within the brain. The signaling may occur through biogenic monoamines, acetylcholine, amino acid, neuropeptides and other gene families. ${ }^{21}$ Memory formation in the brain can be divided into different consecutive 


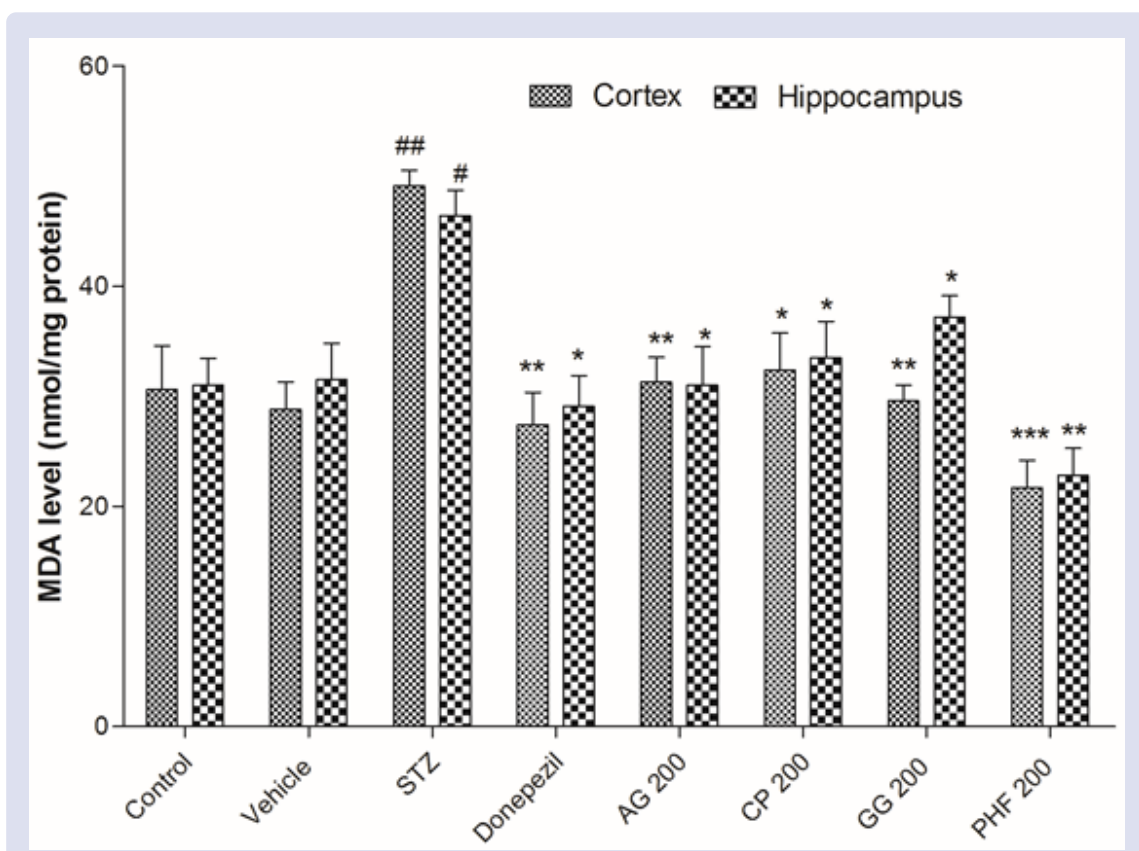

Figure 6: Effect of plant extracts and PHF (200 $\mathrm{mg} / \mathrm{kg})$ on the malondialdehyde (MDA) levels in animals. Results were presented as mean \pm S.E.M., \#Significant difference (\#P $<0.05$ and \#\#P $<0.01$ ) in comparison to the respective brain region of control and vehicle groups and ${ }^{*}$ Significant difference ${ }^{*} \mathrm{P}<0.05,{ }^{* * P}<0.01$ and $\left.{ }^{* * *} \mathrm{P}<0.001\right)$ in comparison to the respective brain region of STZ group.

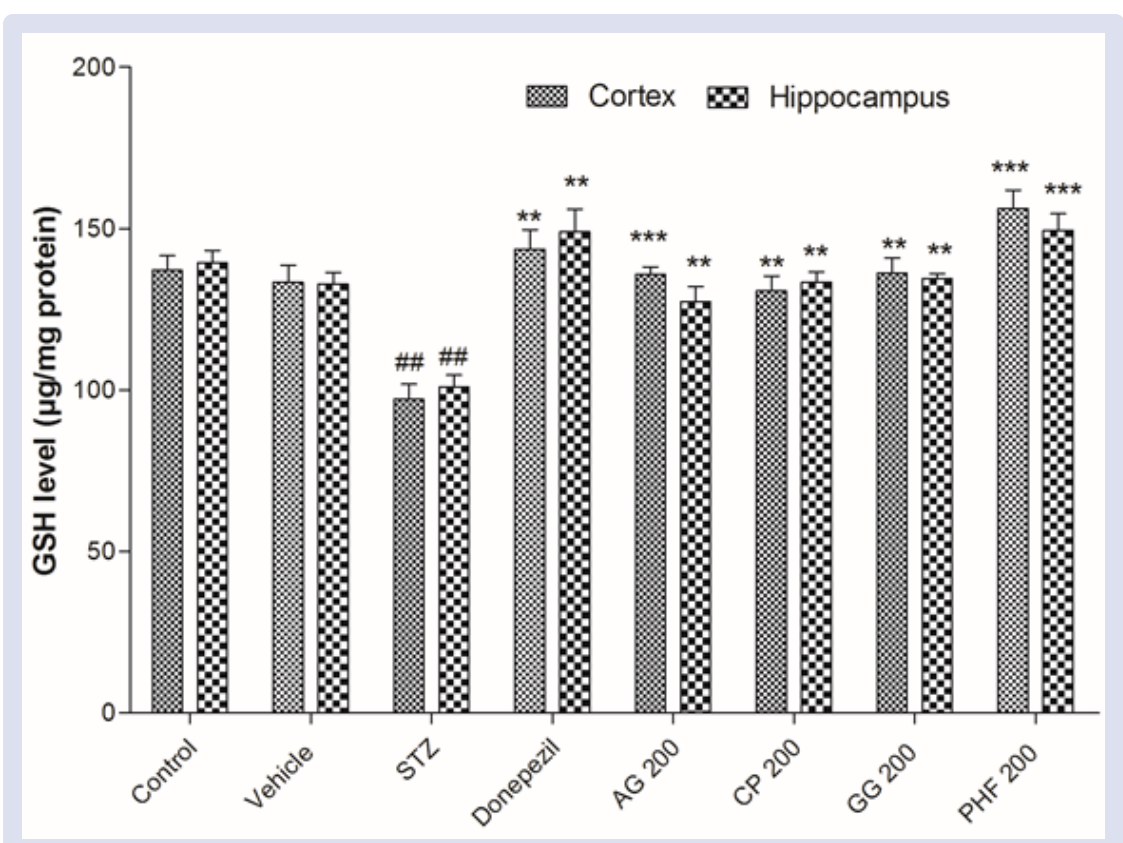

Figure 7: Effect of plant extracts and PHF on the glutathione (GSH) levels in animals. Results were presented as mean \pm S.E.M., significantly different at $\# P<0.05$ and \#\#P 0.01 as compared to control and vehicle groups and significantly different at ${ }^{*} \mathrm{P}<0.05,{ }^{* *} \mathrm{P}<0.01$ and ${ }^{* * * P}<0.001$ as compared to STZ administered group. 


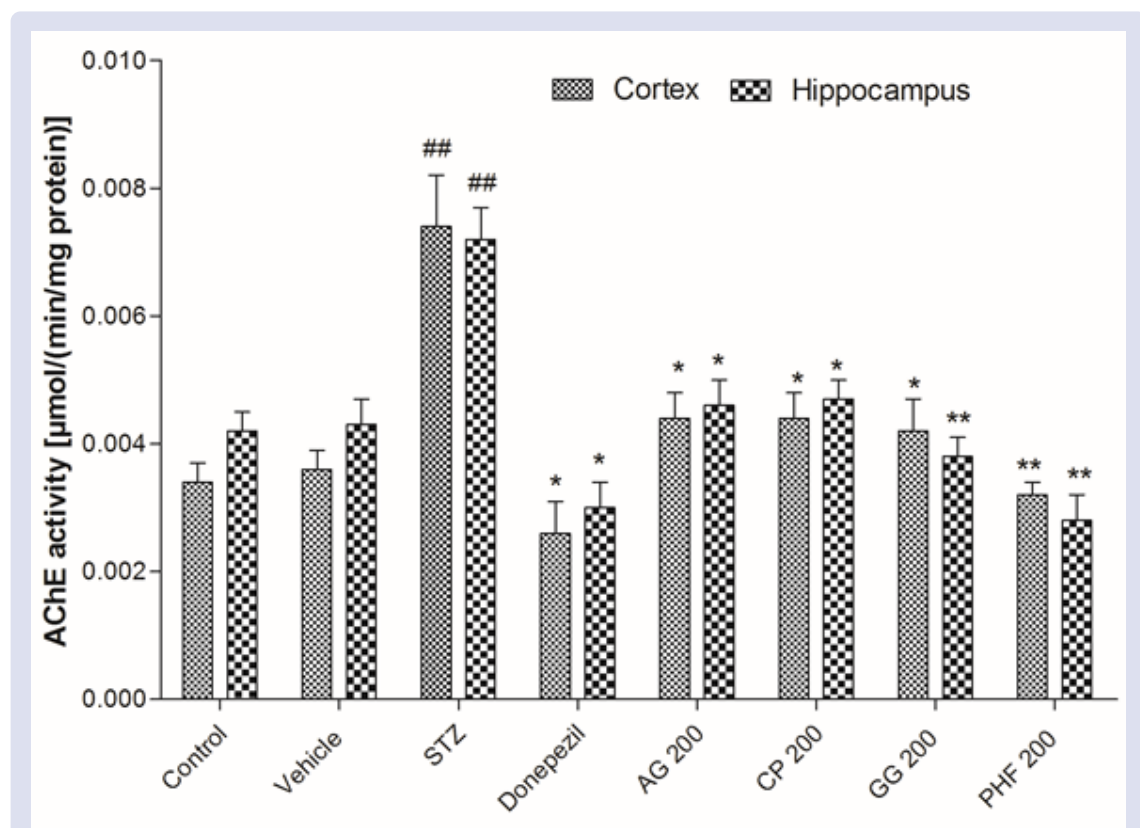

Figure 8: Effect of plant extracts and PHF on acetylcholinesterase activity in animals. Results were presented as mean \pm S.E.M., significantly different at \#P $<0.05$ as compared to control and vehicle groups and significantly different at ${ }^{*} \mathrm{P}<0.05$ and ${ }^{* *} \mathrm{P}<0.01$ as compared to STZ administered group.

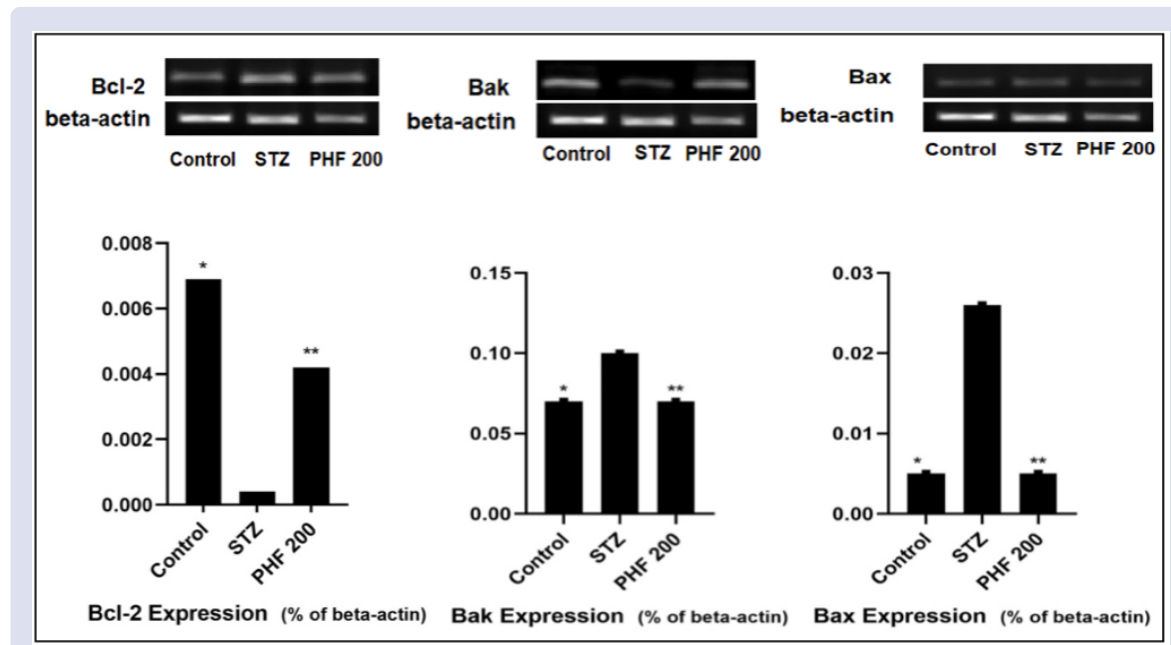

Figure 9: Showing protein expressions of $\mathrm{BCl}-2, \mathrm{Bak}$, and Bax in hippocampus of the experimental mice in RT-PCR analysis. Statistical analysis was carried out by 1-way ANOVA and after that dunnett's multiple comparison assay was done."Denotes significance as compared to control group ( $p$ less than 0.05); "* Denotes significance as compared to STZ (p less than 0.05).

phases such as acquisition, consolidation, retrieval and in some condition, reconsolidation or extinction phases. ${ }^{22}$ The acquisition phase in the learning of new behavior, consolidation phase is the stabilization or storage of earned memory, retrieval phase is accessing the stored memory, reconsolidation is re-evaluation of prior gained memory and extinction phase is inhibition of stored memory. ${ }^{23}$ Serial acquisition of memory is required for learning new information, however, memories are also acquired from past knowledge. Generalization and interference are the memory slots that are produced due to interaction of two different memory traces from behavioral point of view. ${ }^{24}$

The Ayurvedic Polyherbal formulation (PHF) was used for memory enhancement in experimental behavioral animal models due to wide utilization of selected folk medicines and phytotherapy as well. The protocol of the study was designed to evaluate efficacy of these herbs
(A. galanga, G. glabra and C. pluricaulis) in the form of PHF as brain tonic against mental illnesses with a thought to be an effective herbal supplement for neurological disorders. Herbal approach has offered several opportunities to produce new drugs for memory disorders ${ }^{25}$ In this cognitive behavioral study, the PHF was found effective in boosting learning and memory process of animals in different behavioral models i.e. SRT, MWM, PCT and EPM. Results exhibited that STZ losses animal memory while testing in different behavioral models. It has reported that STZ mimics biochemical parameters in animals. ${ }^{26} \mathrm{PHF}$ was found effective in reducing STZ induced toxicity (learning and memory deficit) in animal models along with restoring biochemical enzymatic levels of MDA and GSH. PHF was also found effective in reducing metabolic enzyme activity of acetylcholinesterase. The test drug enhances the level of acetylcholine in the animal brain. In several 


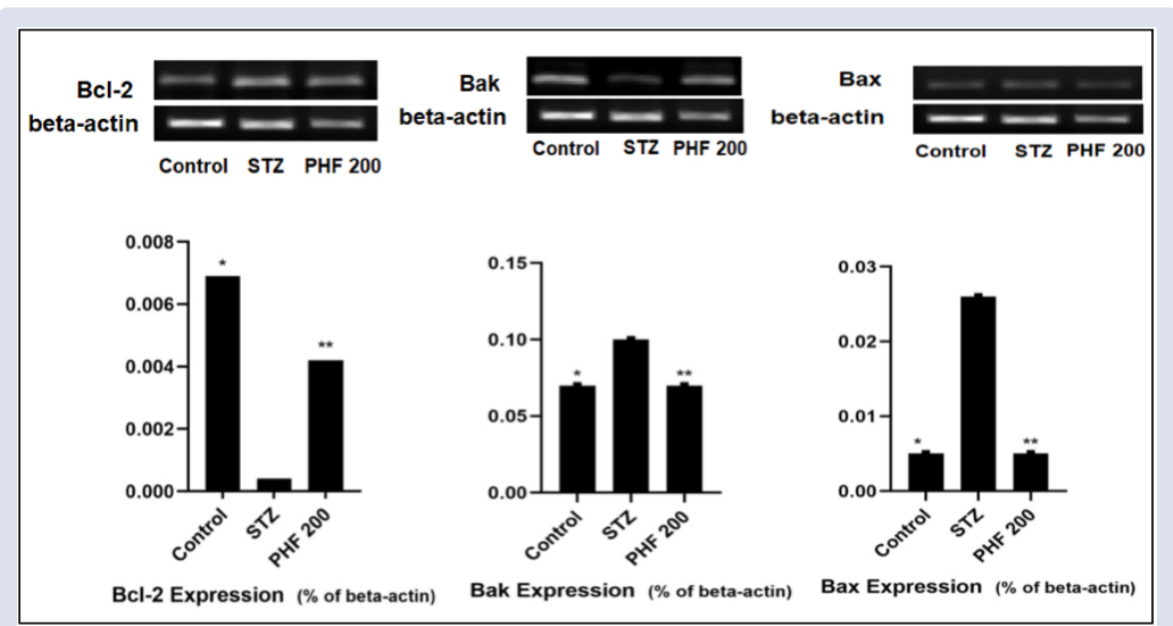

Figure 10: Showing expressions of NR1, NR2B, GAP-43, in hippocampus of the experimental mice in Western blot analysis. Statistical analysis was carried out by 1-way ANOVA and after that dunnett's multiple comparison assay was done. *Denotes significance as compared to control group ( $p$ less than 0.05); ${ }^{* *}$ Denotes significance as compared to STZ (p less than 0.05).

behavioral studies the neuroprotective drugs aimed at preventing the production of free radicals in the brain. Production of free oxidative radicals indicate progression of cognitive decline ${ }^{27} \mathrm{PHF}$ reduced $\mathrm{AChE}$ activity at both cortex and hippocampus regions of the brain in a dosedependent manner. Our findings were matched with the work of Parfitt et al., 2012, that hippocampus consolidate information from short-term memory to long-term memory and plays role in forming, organizing and storing memories. ${ }^{28}$

$\mathrm{Bcl} 2, \mathrm{Bax}$ and Bcl-2 mRNA expression in PHF treated group was significant as compared control and STZ groups. Pro-apoptotic function in cells is showed by Bax and $\mathrm{Bak}^{18}$, however, Bcl-2 is anti-apoptotic in function. Bcl-2 expression in inversely proportional to apoptosis rate that causes cell apoptosis. Present study showed expression of Bak, Bax and Bcl-2 in brain, however the mechanism of expression is yet to be investigated. The western blot technique was used to evaluate NR1 and NR2B expression. Results showed that PHF increased NR1 and NR2B expression. It has reported that NMDA receptor plays immense role in plasticity of synapse as seen in learning and memory. GAP-43 plays role in regulation of growth, neurite outgrowth and synaptic plasticity. The reduction of GAP-43 level in brain is seen due to STZ administration. It was raised by PHF and it may be attributed to recovery of synaptic plasticity in the brain.

\section{CONCLUSION}

It can be concluded from the study that PHF alleviated amnesia in STZ treated rats by improving cholinergic function, reduction of oxidative stress and enhancement of behavior. Thus, PHF may be an alternative compound for the treatment of memory loss memory deficit cases.

\section{DECLARATION}

Author declare no conflict of interest.

\section{ACKNOWLEDGEMENT}

Authors are thankful to the institute for providing all facilities required during the work.

\section{REFERENCES}

1. Lawrence E, Vegvari C, Ower A, Hadjichrysanthou C, De Wolf F, Anderson RM. A Systematic Review of Longitudinal Studies Which Measure Alzheimer's Disease Biomarkers. J Alzheimers Dis. 2017;59(4):1359-79.
2. Esquerda-Canals G, Montoliu-Gaya L, Güell-Bosch J, Villegas S. Mouse Models of Alzheimer's Disease. J Alzheimers Dis. 2017;57(4):1171-83.

3. Logroscino G, Traynor BJ, Hardiman O, Chi A, Mitchell D, Swingler RJ. Incidence of amyotrophic lateral sclerosis in Europe. Journal of Neurology, Neurosurgery, and Psychiatry. 2010;81:385-90.

4. Nabi NU, Neeraj K, Ravi K, Preeti K. Natural Remedies for Improving Learning and Memory-Review. Int. J. Pharm. Phytopharmacol. Res. 2013;3(2):161-5.

5. Tabassum N, Rasool S. Natural Cognitive Enhancers. Journal of Pharmacy Research, 2012;5(1):153-60.

6. Howes MJ, Houghton PJ. Plants used in Chinese and Indian traditional medicine for Improvement of memory and cognitive function. Pharmacology Biochemistry Behavior. 2003;75:513-27.

7. Govindarajan R, Vijayakumar M. Antioxidant approach to disease management and the role of 'Rasayana' herbs of Ayurveda. Journal of Ethnopharmacology. 2005;99:165-78.

8. Tang X, Xu C, Yagiz Y, Simonne A, Marshall MR. Phytochemical profiles, and antimicrobial and antioxidant activities of greater galangal [A/pinia galanga (Linn.) Swartz.] flowers. Food Chem. 2018;255(8):300-8.

9. Khumpirapang N, Chaichit S, Jiranusornkul S, Pikulkaew S, Müllertz A, Okonogi S. In vivo anesthetic effect and mechanism of action of active compounds from Alpinia galanga oil on Cyprinus carpio (koi carp). Aquaculture. 2018;496(1):17684.

10. Yang R, Yuan BC, MaYS, Zhou S, LiuY. The anti-inflammatory activity of licorice, a widely used Chinese herb. Pharm. Biol. 2017;55(1):5-18.

11. Iqbal I, Khanam R, Hassan S, Roou A, Moshahid Alam M, Islam A, Thakur S, Athara F. New insights into the antioxidant and apoptotic potential of Glycyrrhiza glabra L. during hydrogen peroxide mediated oxidative stress: An in vitro and in silico evaluation. Biomed Pharmacother. 2017;94:265-79.

12. Sairam K, Rao CV, Goel RK. Effect of Convolvulus pluricaulis Chois on gastric ulceration and secretion in rats. Indian J Exp Biol 2001;39(4):350-4.

13. Ravichandra VD, Ramesh C, Sridhar KA. Hepatoprotective potentials of aqueous extract of Convolvulus pluricaulis against thioacetamide induced liver damage in rats. Biomed Aging Pathol. 2013;3(3):131-5.

14. Prasad SB, Sharma A. Antioxidant activity of Convolvus plauricalis. Invent Rapid Plant Act 2011;79(11).

15. Tota S, Kamat PK, Awasthi H, Singh N, Raghubir R, Nath C, Hanif K. Candesartan improves memory decline in mice: involvement of AT1 receptors in memory deficit induced by intracerebral streptozotocin. Behav. Brain Res. 2009;199:235-40

16. Goverdhan P, Sravanthi A, Mamatha T. Neuroprotective effects of meloxicam and selegiline in scopolamine-induced cognitive impairment and oxidative stress. Int J. Alzheimers Dis. 2012:407-16.

17. Kulkarni SK, Singh K, Bishnoi M. Elevated zero maze: a paradigm to evaluate antianxiety effects of drugs. Methods Find. Exp. Clin. Pharmacol. 2007;29:3438

18. Mo $Y$, Wan $R$, Zhang $Q$. Application of reverse transcription-PCR and real-time PCR in nanotoxicity research. Methods Mol Biol. 2012;926:99-112. 
19. Taylor SC, Posch A. The Design of a Quantitative Western Blot Experiment. Hozak P, editor. Biomed Res Int. 2014.

20. Barulli MR, Piccininni M, Di C, Musar C, Grasso A, Tursi M, et al. Episodic memory and learning rates in amyotrophic lateral sclerosis without dementia. Cortex. 2019;117:257-65.

21. Gotzsche CR, Woldbye DP. The role of NPY in learning and memory. Neuropeptides. 2016;55:79-89.

22. Samuel N, Taub AH, Paz R, Raz A. Implicit aversive memory under anaesthesia in animal models: a narrative review. Br J Anaesth. 2018;121(1):219-32.

23. Pape HC, Pare D. Plastic synaptic networks of the amygdala for the acquisition, expression, and extinction of conditioned fear. Physiol Rev. 2010;90:419-63.

24. Herszage J, Censor N. Modulation of learning and memory: a shared framework for interference and generalization. Neuroscience. 2018;392:270-80.
25. Elisa T, Paula A, Laiz P. Taraxerol as a possible therapeutic agent on memory impairments and Alzheimer's disease: Effects against scopolamine and streptozotocin-induced cognitive dysfunctions. Steroids. 2018;132(1):5-11.

26. Butterfield DA, Lauderback CM. Lipid peroxidation and protein oxidation in Alzheimer's disease brain: potential causes and consequences involving amyloid $\otimes$-peptide-associated free radical oxidative stress. Free Radic. Biol. Med. 2002;32:1050-60.

27. Selkoe DJ. Cell biology of protein misfolding: The examples of Alzheimer's and Parkinson's diseases. Nat. Cell Biol. 2004;6:1054-61.

28. Parfitt GM, Campos RC, Barbosa AK, Koth AP, Barros DM. Participation of hippocampal cholinergic system in memory persistence for inhibitory avoidance in rats. Neurobiol. Learn. Mem. 2012;97:183-8.

\section{GRAPHICAL ABSTRACT}

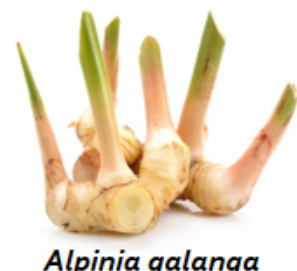

rhizomes

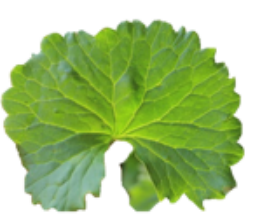

Convolvulus pluricaulis leaves

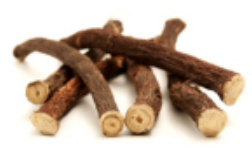

Glycyrrhiza glabra rhizomes

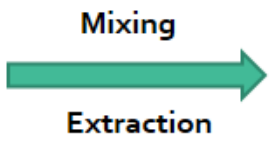

Extraction

\section{Polyherbal formulation} (PHF) dried

PHF SUSPENSION IN STREPTOZOTOCIN INDUCED MEMORY LOSS EXPERIMENTAL ANIMAL MODELS
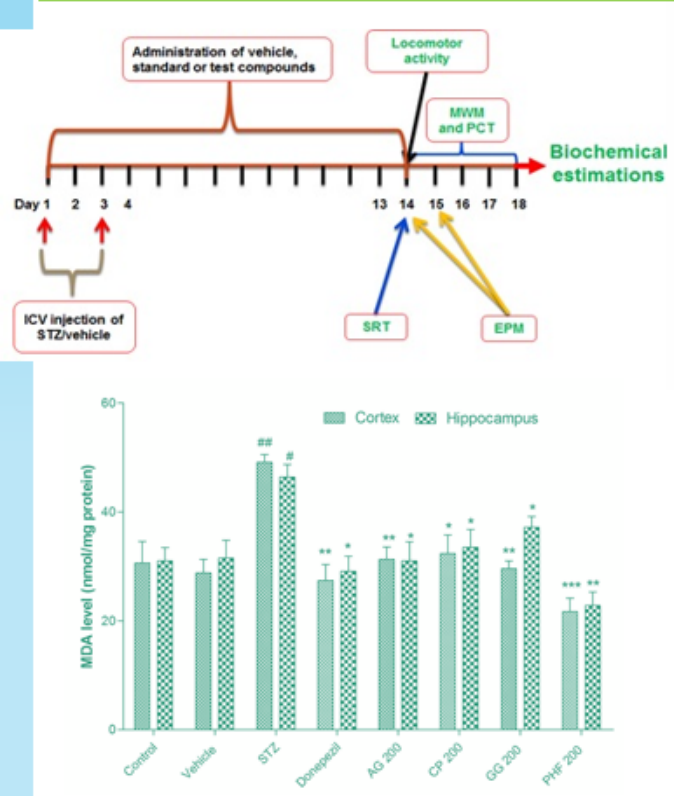

MDA level in brain

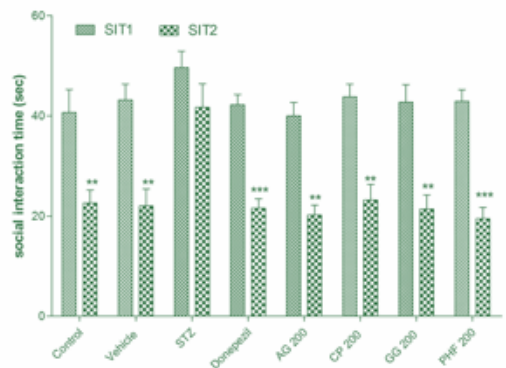

Social recognition test

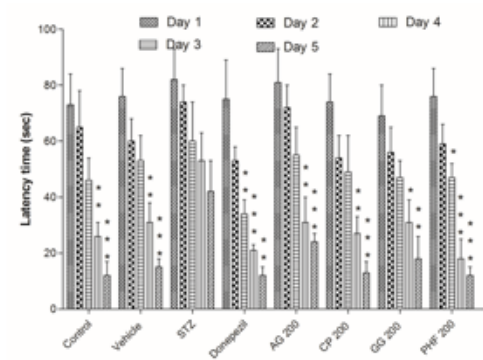

Morris water maze test

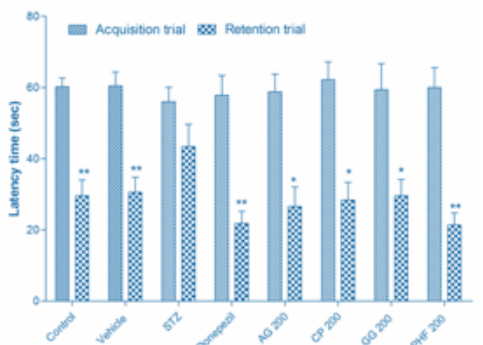

Elevated plus maze test 


\section{ABOUT AUTHORS}

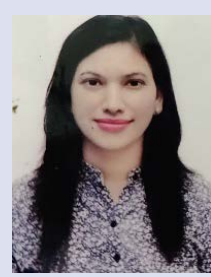

Deepa Shukla is Ph D scholar in Amity Institute of Pharmacy, Amity University Uttar Pradesh, Lucknow Campus, India. She completed her B Pharm and M Pharm from Dr. A.P.J. Abdul Kalam Technical University, Uttar Pradesh. She has been teaching and researching for more than 6 years.
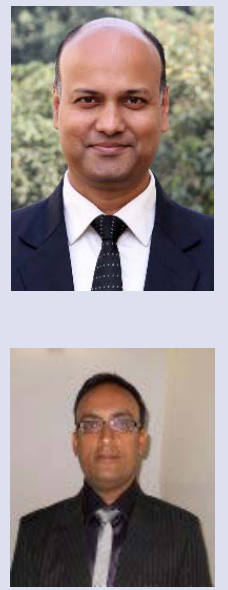

Dr. Sajal Srivastava is currently working as a Dy Director \& Associate professor at the Department of Pharmaceutical Chemistry, Amity Institute of Pharmacy, Amity University Uttar Pradesh, Lucknow Campus, India. He is Head of Department of Pharmaceutical Chemistry. He has over 17 years of experience in teaching Phytochemistry, Medicinal Chemistry and Instrumental Techniques. Dr. Srivastava's main research area is medicinal plants and chemistry of heterocyclic compound. He has also acquired expertise in the development of nasal dosage form. He has authored many book chapters and research articles in peer reviewed journals. In his research area many post-graduate scholars are pursuing their master and doctoral degree.

Dr TALHA JAWAID is an Assistant Professor of Pharmacology college of Medicine at AL-IMAM BIN SAUD ISLAMIC UNIVERSITY, Riyadh, Kingdom of Saudi Arabia. He graduated from Rajiv Gandhi University of health sciences, Bangalore and finished his PhD from Integral University, Lucknow. He Participated in teaching Pharmacology to all medical professional school students. He has 15 years of teaching and research experience. Dr. Talha Jawaid main research area is neuropharmacology and cardiovascular pharmacology. He has published various research paper in peer review journals. He has published one book in his credit.

Cite this article: Shukla D, Srivastava S, Jawaid T. Learning and Memory Enhancing Activity of Polyherbal Formulation on Streptozotocin Induced Memory Impairment in Rats via Reducing Mitochondria-Targeted Cytochrome. Pharmacog J. 2021;13(1): 230-40. 